\title{
Payment for plasma raises ethical issues
}

A n Ontario-based company is now compensating donors for plasma, giving rise to a divide in the medical community about the safety and ethics of paying for blood.

Canadian Plasma Resources is waiting on licence approval from Health Canada, but is already paying plasma donors in a pilot phase that's been approved by Institutional Review Board Services, according to CEO Barzin Bahardoust. The company has paid about 100 donors, so it can do quality testing and train staff at a site in downtown Toronto. There are plans to open another Toronto site as well as one in Hamilton, Ontario.

The Ontario Ministry of Health and Long-Term Care, Hemophilia Ontario, individual doctors and victims of tainted blood have expressed concern that paying for plasma poses risk to recipients and donors.

On July 22, Ontario's newly reelected Liberal government introduced a bill that would ban paying donors. Approval seems likely, given the Liberals hold a majority.

Those who oppose paying donors often cite the 1997 report from the Commission on the Blood System in Canada, which recommended that all blood and blood product donation be publicly administered and voluntarily donated after 1000 individuals contracted HIV and 33000 contracted hepatitis $\mathrm{C}$ from blood products given by improperly screened donors.

But Canadian Blood Services and Health Canada say plasma from compensated donors, which is used for pharmaceutical therapies made from plasma protein not for direct transfusion, is safe.

"There are strict regulations in place which require screening and testing of all donors as well as the use of techniques to eliminate contaminates and viruses," says William Wells, media relations officer for Health Canada. Since the introduction of these processes, HIV, hepatitis $\mathrm{C}$ and hepatitis B have never been transmitted through the use of plasma pharmaceutical products

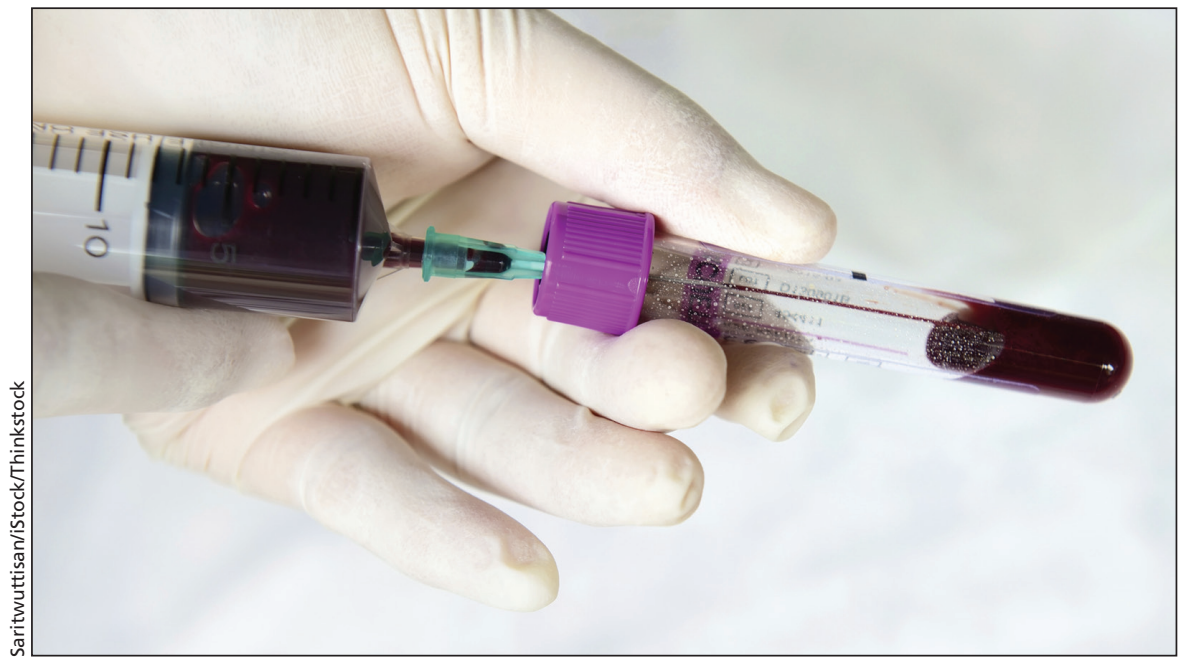

Stringent testing ensures that HIV, hepatitis C and hepatitis B are not transmitted through the use of plasma pharmaceutical products from paid donors, says Canadian Blood Services.

from paid donors, adds Canadian Blood Services' CEO Dr. Graham Sher.

It's against Canadian Blood Services' policy to pay for blood or blood products, but it would be impossible for Canada to meet its growing plasma need by relying solely on voluntary donors. Only $30 \%$ of the plasmaderived immunoglobulin is now supplied through the voluntary donor system; the rest is purchased from US companies that pay donors, says Sher.

Bahardoust says his company aims to discourage "people who are unsuitable" by paying not in cash but in their choice of a \$25 charitable donation to Toronto's Hospital for Sick Children or a \$25 Visa gift card that can't be converted to cash. Tests, like a physical exam, vitals testing and serum protein analysis are all done "for the safety of the donor."

Canadian Plasma Resources is not the first company to pay donors. Cangene, a Winnipeg-based pharmaceutical company, has been paying plasma donors for three decades. It was launched to collect $\mathrm{Rh}$-negative plasma to treat pregnant women, but also collects plasma for pharmaceutical purposes.

Dr. Ryan Mieli, a Saskatoon-based family doctor and vice-chair of Canadian Doctors for Medicare, says that given the testing methods, he's not worried about the risks to recipients of paidplasma derived pharmaceuticals, but he is concerned about risks to donors.

Speaking as an individual, not for his organization, Mieli says that given the locations of the clinics and the amount paid, Canadian Plasma Resources is "really targeting people who are low-income. They're profiting off of poverty ... . I think that raises some significant ethical issues."

A review article in the Journal of Clinical Apheresis found that while adverse reactions to the donation of blood components were less frequent than with whole blood donation, the risk of reactions leading to hospitalization were greater in the former, and that the long-term effects of frequent blood component donation requires additional study. (Because the donor's red blood cells are returned after the plasma is separated out, donors can give plasma every week, while whole blood donors can give every eight weeks.)

Mieli says that "If we absolutely do have to pay people to get plasma, we should do it through Canadian Blood Services." - Wendy Glauser, Toronto, Ont.

CMAJ 2014. DOI:10.1503/cmaj.109-4855 